\title{
El periodismo en la obra de José Ortega y Gasset (en el cincuentenario de su muerte)
}

\section{Ignacio Blanco Alfonso}

Profesor de Redacción Periodística

Universidad CEU San Pablo de Madrid.

Investigador del Centro de Estudios Orteguianos

\section{Resumen:}

José Ortega y Gasset fue al mismo tiempo que filósofo o intelectual, escritor, periodista, catedrático, político... El cincuentenario de su muerte es una buena ocasión para descubrir aquellos aspectos de su biografía menos estudiados a causa de la preponderancia de los estudios sobre su filosofía. El presente artículo trata de vincular el periodismo con la biografía de Ortega, y los analiza en su obra. El balance final evidencia que, en la circunstancia orteguiana, el periodismo fue determinante tanto en la forma como en el fondo de su filosofía.

Palabras clave:

Vocación periodística, periodismo combativo, periodismo contemplativo, proyectos editoriales.

\section{Abstract:}

Jose Ortega y Gasset was at the same time a philosopher, an intellectual, a writer, a journalist, a professor, a politician... The fiftieth anniversary of his death is a good occasion to discover those aspects of his biography less studied because of a greater interest in his philosophy than in his biography or the nonphylosophycal genres he cultivated. The present article tries to relate his journalism and biography, and analyze them in connection with Ortega's philosophical work. The conclusion evidences in the circumstances of his life, journalism determined much of the form and the substance of his philosophy.

Key words:

Journalistic vocation, engaged journalism, disengaged journalism, editorial projects. 


\section{Introducción}

No precisa José Ortega y Gasset (1883-1955) de efemérides para ser releído o recordado, aunque ciertamente los aniversarios siempre representan ocasiones propicias para revisar el estado de una cuestión determinada. Este año se conmemora el cincuenta aniversario de la muerte del gran filósofo español contemporáneo, lo que ha propiciado que varias iniciativas relacionadas con la difusión de su pensamiento concurran en el tiempo. Algunas de ellas han sido puntuales, como el magnífico Congreso Internacional que tuvo lugar el pasado mes de octubre en Madrid, así como varios simposios celebrados por toda Europa y América. Otras iniciativas, sin embargo, son de mayor calado y repercusión en el tiempo, como la aparición de unas nuevas Obras completas (Taurus - Fundación José Ortega y Gasset), edición canónica ya imprescindible para explorar el pensamiento del filósofo.

Además de la efeméride, sucede que la circunstancia presente sitúa al pensamiento de José Ortega y Gasset en el frontispicio de muchos de los problemas que nuestro país y nuestro continente tienen planteados, como el complicado proceso de construcción europea, la vertebración de España a la luz de la reforma de los estatutos de autonomía, el papel de la Universidad en la sociedad contemporánea dada la reforma del sistema educativo... Es decir, el devenir histórico español y europeo ha propiciado que Ortega sea, más que nunca, un filósofo imprescindible para el siglo XXI.

La vigencia de su pensamiento consiste en que el autor madrileño fue capaz de anticipar muchos de los problemas que hoy azotan nuestra civilización, y años antes de que ocurrieran, Ortega los describió con asombrosa nitidez. A él debemos fundamentos antropológicos de tanta envergadura como la teoría de la rebelión de las masas y la devaluación de la cultura; la formulación de la "razón vital" y el imperativo de que cada individuo asuma su destino; la invertebración de España y la función de las regiones y los municipios en la construcción de una patria común; la europeización de España y la visión de los "Estados Unidos de Europa"; la misión de la Universidad como poder social de mayor rango espiritual, etcétera.

Todo ello bastaría para que un artículo sobre Ortega y Gasset encontrara asiento en este número de doxa. Sin embargo, hay otra razón -que nada tiene que ver con el cincuentenario- para justificar el acercamiento de Ortega con los lectores de una revista de estudios de comunicación, y es su ineludible condición de periodista. Si se explora esta faceta de su extensa biografía, se topará con el perfil de un periodista integral que fue, al tiempo que catedrático, fundador de revistas y periódicos (como Faro en 1908, España en 1915, El Sol en 1917, Revista de Occidente en 1923, Crisol y Luz en 1931), editorialista, cronista de viajes, crítico literario, comentarista político e incluso necrólogo, pues entre sus artículos se espigan alrededor de una docena de necrológicas que, como el conjunto de su obra, son dignas de análisis y estudio en las facultades de comunicación.

Sobre este horizonte periodístico de la personalidad orteguiana quiero exponer algunas consideraciones que nos permitan comprender plenamente por qué el periodismo fue tan determinante en la 
obra de Ortega. No obstante, antes de entrar en materia, creo que la efeméride me obliga a escribir una anotación al margen, como una glosa, relacionada con las nuevas Obras completas y, por extensión, con la actividad del Centro de Estudios Orteguianos, en cuyo equipo de profesores recae la investigación y edición de las mismas.

\section{Nuevas Obras completas}

Cincuenta años después de la muerte de José Ortega y Gasset, la Fundación que lleva su nombre ha acometido uno de los proyectos más ambiciosos desde su creación: la publicación más exhaustiva y cuidada de la obra de Ortega.

Hay que indicar que la tradición de reunir sus Obras se inició en 1932, y que a partir de 1946 se quiso que fueran completas. A este empeño han contribuido tanto sus hijos Miguel, Soledad y José, como algunos discípulos, entre los que sobresale Paulino Garagorri, a quien debemos la edición en doce volúmenes publicada por Alianza Editorial y Revista de Occidente en 1983 (no por casualidad el año del centenario del nacimiento de Ortega). Esta colección de Garagorri ha sido, hasta ahora, la versión más completa, pero reparemos en que han transcurrido 23 años desde entonces, periodo en el que, como no podía ser de otra forma, el pensamiento de Ortega ha seguido despertando vocaciones investigadoras. Buena parte del fruto de estas investigaciones se proyectan ahora en el trabajo de edición de las nuevas Obras completas, que con razón se califican de "canónicas", pues representan el modelo más depurado de la obra del autor.

Tal y como se explica en el prólogo a la nueva edición, cuando el pensador muere en 1955 deja un corpus textual dividido en tres grandes bloques: por un lado, sus Obras completas editadas por Revista de Occidente en 1955 (para la nueva edición, éste es el texto de referencia porque es el último revisado por Ortega en vida); por otro lado, los textos que fueron publicados en diversos soportes pero que, por distintos avatares, no pasaron a esa colección del 55 (por ejemplo, los artículos publicados en el periódico bonaerense La Prensa, entre 1911 y 1913); por último, cuando el filósofo muere quedó inédita buena parte de sus escritos, muchos de los cuales aún no han visto la luz, es decir, su obra póstuma. Por lo tanto, podemos afirmar que, en sentido estricto, todavía no disponíamos de la "obra completa" del autor.

Dada esta situación, y para no enredar al lector en cuestiones técnicas que nada le aprovecharían, sintetizaré las tres novedades más significativas de la nueva edición:

1. $\quad$ Fijación del corpus, para lo cual se ha añadido a la obra conocida el resultado de la investigación en el Archivo de la Fundación José Ortega y Gasset y en hemerotecas españolas y extranjeras. También se han expurgado libros colectivos en los que se tenía noticia o sospecha de que Ortega había participado con algún capítulo. Gracias a esta labor se ha podido elaborar un plan de la 
obra dividida en diez tomos: los seis primeros reúnen la obra en vida, mientras que los cuatro últimos estarán dedicados a la obra póstuma. Además, la estructura interna del conjunto es cronológica, no como hasta ahora, lo que permitirá una lectura diacrónica de la obra pues cada texto aparece ubicado en el momento en que vio la luz por primera vez (este criterio no se ha respetado para los libros antológicos reunidos por el propio Ortega, que se han mantenido unidos, aunque la noticia bibliográfica que aparece al final de cada tomo aclara la primera publicación, generalmente en prensa, de cada capítulo o artículo del mismo).

2. ${ }^{\circ} \quad$ Fijación del texto, para lo cual se han cotejado electrónicamente cada una de las versiones de los escritos orteguianos publicadas en vida del autor, lo que ha permitido una profunda depuración de erratas y malas lecturas perpetuadas en el tiempo.

3. ${ }^{\circ}$ Aparato crítico. Una de las novedades más importantes de esta edición es el aparto crítico que cierra cada tomo. El lector encontrará en sus páginas cuatro apartados: a) Notas a la edición, que narran la peripecia de cada escrito cuando es necesario; b) Noticia bibliográfica, que ofrece la cronología y los lugares en que cada escrito apareció publicado; c) Apéndice, donde se señalan todas las variantes textuales detectadas en el cotejo y corregidas en esta versión, y d) Índice onomástico y toponímico, que permite hacer una lectura fragmentaria de la obra de Ortega siguiendo las referencias a los cientos de personajes y lugares que pueblan sus páginas.

Todo este aparato crítico llevado al colofón del tomo permite, a mi modo de ver, que se pueda recibir a Ortega sin interrupciones de tipo científico-crítico. A la vez, creo que esta edición nos permitirá leer a un Ortega a la altura de nuestro tiempo y será, no lo olvidemos, la versión por la que el gran filósofo español hable a las futuras generaciones.

Todo lo expuesto hasta aquí podría llevar a pensar que el interés por Ortega tiene que ver con que el cincuentenario de su muerte ha puesto de moda al autor, pero nada más lejos de esa realidad. De la demanda social de su pensamiento da buena cuenta la Revista de Estudios Orteguianos, nacida en el 2000 y editada por el Centro de Estudios Orteguianos.

Este centro de investigación nació, precisamente, para conservar y difundir el legado intelectual de Ortega, y sirve de lugar de encuentro y de referencia mundial para cuantos investigadores y estudiosos ha generado y sigue generando la obra del filósofo. En cuanto a la revista, basta indicar que publica una media de 275 páginas cada seis meses (que se dice pronto) dedicadas exclusivamente a la obra y persona de Ortega. Desde su nacimiento, han visto la luz en sus páginas alrededor de 70 artículos científicos, y se han dedicado más de 600 páginas a material inédito del Archivo. Como no se le escapa al lector, esta proyección editorial no sería posible sin el interés que sigue suscitando el pensamiento orteguiano transcurrido un siglo desde sus primeros artículos periodísticos.

Para hacernos una idea del potencial bibliográfico que genera este autor, consideremos que desde 1998 se han publicado más de 600 estudios relacionados con su obra, teniendo en cuenta libros, mo- 
nografías y artículos de investigación. Además, resultaría imposible inventariar las tesis doctorales y tesinas en torno al pensador, o las nuevas ediciones, reediciones y reimpresiones de sus libros más conocidos. Cabe destacar que, tan sólo en los últimos años, las obras de Ortega se han traducido a todos los idiomas de Europa del Este, como el serbio, húngaro, croata, rumano, ruso, polaco, turco, búlgaro, lituano..., varios orientales como el coreano o el japonés, y otros como el hindi, sin mencionar las lenguas a las que la obra de Ortega es traducida sistemáticamente, como el portugués, francés, alemán, italiano, inglés...

Esta profusión de datos no sólo muestra la universalidad de Ortega, sino que certifica la atención con que la sociedad sigue leyendo su obra. Además, debe alentar a los investigadores interesados en este pensador a que emprendan nuevas vías de exploración, porque, como la Revista de Estudios Orteguianos evidencia en cada número, su obra está todavía, en gran medida, por descubrir ${ }^{1}$.

Y precisamente de esta parte que permanece en la penumbra trata el presente artículo, del que paso a ocuparme sin más preámbulos.

\section{El periodismo en la obra de José Ortega y Gasset $^{2}$}

Párrafos atrás mencioné que la biografía de Ortega nos ofrece el perfil de un periodista integral. Escojo a conciencia el adjetivo, pues "integral" nos dice de algo o de alguien que es global o total, y creo que

${ }^{1}$ Una de las secciones fijas de la revista está dedicada a expurgar los "Documentos de Archivo". Aquí se ofrece al lector, en cada entrega, material inédito de dos tipos: por un lado, las "Notas de trabajo" manuscritas por Ortega en el margen de lo que fueron sus textos definitivos y cuya lectura nos permite acercarnos al autor en un momento tan crucial como la preparación de sus trabajos y conocer por qué vericuetos deambulaba su mente; por otro lado, el "Itinerario biográfico", con grandes dosis de material gráfico, que trata de rescatar del Archivo diversos momentos vitales de Ortega para construir una biografía más humana y precisa de su persona.

${ }^{2}$ No es la primera vez que me ocupo de esta cuestión, por lo que el lector puede encontrar más información en Blanco Alfonso, Ignacio (2005): El periodismo de José Ortega y Gasset, Madrid: Biblioteca Nueva - Fundación José Ortega y Gasset; - (2006) “Ortega o el periodismo circunstancial", Revista de Occidente, n. ${ }^{\circ}$ 300, mayo, pp. 49-70; - (2005): "Para una lectura de la obra periodística de Ortega y Gasset”, en Aportes. Revista de Historia Contemporánea, n. ${ }^{\circ}$ 57, pp. 45-61; - (2004): “Los géneros periodísticos en José Ortega y Gasset”, en Benavides Delgado, Juan et al. (eds.): Información, producción y creatividad en la comunicación, Madrid: Fundación General de la Universidad Complutense de Madrid - Ayuntamiento de Madrid, pp. 731-754; - (2001): “Modelos, métodos y formatos de las críticas literarias de José Ortega y Gasset", en Revista de Estudios Orteguianos, n. 2 , mayo 2001, pp. 165-174.

Otros lugares en los que el lector puede indagar en los aspectos relacionados exclusivamente con la faceta periodística de Ortega son (por orden alfabético): Ayala, Francisco (1974): "Ortega y Gasset, crítico literario", en Revista de Occidente, 2. época, n. ${ }^{\circ} 140$, noviembre 1974; Fernández Sanz, Fernando (1958): “Ortega y Gasset como periodista”, en Gaceta de la prensa española, n. ${ }^{\circ}$ 12; Fuentes, Juan Francisco (1997): “España, olvido y vigencia de una empresa orteguiana”, en Revista de Occidente, n. ${ }^{\circ}$ 193; Gullón, Ricardo (1956): “Ortega, crítico literario”, en Sur (Buenos Aires), n. ${ }^{\circ}$ 241; López Campillo, Evelyne (1972): La Revista de Occidente y la formación de las minorías, Madrid: Taurus; López Morillas, Juan (1957): “Ortega y Gasset y la crítica literaria”, en Cuadernos Americanos (México), n. ${ }^{\circ}$ 16; Ortega Munilla, José (1997): “Tres cartas a su hijo sobre cómo hacer una revista (España)", en Revista de Occidente, 3. ${ }^{a}$ época, n. ${ }^{\circ}$ 193; Redondo, Gonzalo (1970): Las empresas políticas de José Ortega y Gasset, Madrid: Rialp, 2 vol.; 
con este sentido hay que aplicarlo a la faceta periodística de Ortega. Trataremos, en este artículo, de analizarla desde diferentes perspectivas.

\section{La forja de una vocación}

Desde muy joven sintió el filósofo la tentación de utilizar la letra impresa para comunicarse. Aunque se ha repetido muchas veces -y equivocadamente- que su primer artículo fue "Glosas", aparecido en la revista Vida Nueva ${ }^{3}$ en diciembre 1902, lo cierto es que algunos meses antes ya había publicado Ortega en el Faro de Vigo su primera crítica literaria: “Glosa. A Ramón del Valle-Inclán” (28 de agosto de 1902) La colaboración con Vida Nueva fue, pues, su segunda aparición pública, y si me apuran, la tercera colaboración periodística, según la anécdota poco conocida que a continuación referiré.

Preparando un itinerario biográfico conmemorativo del cincuenta aniversario de la muerte del pensador $^{5}$, me dediqué a expurgar las necrológicas sobre Ortega publicadas en octubre de 1955 en la prensa nacional y extranjera, cuyos recortes se conservan en el Archivo de la Fundación. Entre los centenares de documentos que consulté, me llamó la atención una magnífica doble plana aparecida en El Nacional, de Caracas, el 3 de noviembre de 1955. Ocupaba el faldón, a 8 columnas, un artículo firmado por su hermano Eduardo Ortega y Gasset, titulado con la resonante expresión "Bebiotai, Bebiotai... Ha vivido, Ha vivido”. Como necrológica, el texto no tiene desperdicio, pues a la valoración vital del hombre público que fue Ortega, acompaña Eduardo los recuerdos íntimos de su hermano, lo que nos permite conocer mucha información que jamás encontraríamos en las biografías oficiales. Pues bien, entre estos recuerdos Eduardo rememora "la primera experiencia periodística de José":

"El más joven de los hermanos de mi madre, Ramón Gasset, [...] por aquellos días había instalado una imprenta en la calle de Lagasca. Las máquinas y la tipografía eran modernísimas, así como el taller de fotograbado. Nos atrajo aquel suntuoso juguete. Nos permitía realizar un sueño, el de fundar una Revista.

Romano, Vicente (1977): José Ortega y Gasset, publicista, Madrid: Akal; Villar Dégano, Juan F. (1983): “Algunas notas sobre Ortega y Gasset como crítico de arte" en Letras de Deusto, n. $^{\circ} 26$.

${ }^{3}$ La revista Vida Nueva acogió la segunda colaboración del joven Ortega en un medio de comunicación. Aunque las historiadoras María Cruz Seoane y María Dolores Sáiz explican que "no pudo publicar en ella Ortega su primer juvenil artículo el 1 de diciembre de 1902, tal como recogen sus Obras completas, porque por entonces ya había desaparecido la revista" (cfr. Historia del Periodismo en Español. El siglo XX, 1898-1936, vol. III, Madrid: Alianza Editorial, p. 201), lo cierto es que sí publicó esas "Glosas" en Vida Nueva y que aún existía la revista en la fecha mencionada. De hecho, en la Fundación José Ortega y Gasset yo he visto el ejemplar que contenía aquella colaboración.

${ }^{4}$ Vicente Cacho Viu en el "Prólogo" a Cartas de un joven español (edición de Soledad Ortega, Madrid: El Arquero, 1991) ya se refiere a esta crítica literaria como el primer artículo publicado por Ortega en un medio de comunicación. Esta "Glosa A Ramón del Valle-Inclán" se reeditó en Revista de Occidente, n. ${ }^{\circ}$ 44-45, nov.-dic. 1966, pp. 364-366, y actualmente abre el primer tomo de las nuevas Obras completas.

${ }^{5}$ Cfr. Blanco Alfonso, Ignacio (2005): “Otoño de 1955: conmoción por la muerte de José Ortega y Gasset”, Revista de Estudios Orteguianos, n. ${ }^{\circ}$ 10/11, pp. 78-150. 
Así fundamos el periódico que se tituló «Las Primeras Armas». Realmente no fue periódico. Carecía de periodicidad, ya que sólo gimieron las prensas en el parto de su primer número. ¡Quién hubiera podido conservar un ejemplar! Nuestras vidas han sido harto agitadas, singularmente la mía, para tener archivos...

Para la historia de mi hermano tiene este episodio que muy pocos conocen, el valor de consignar que en «Las Primeras Armas» publicó su primer trabajo.

La máquina de doble reacción iba entregándonos los ejemplares con sus dedos de madera. Muy grande era nuestra ilusión al retirarlos. Repasábamos con entusiasmo aquella preciosa tipografía en la que se destacaban unas elegantes letras Elzevir. El olor de la húmeda tinta nos era familiar. Se iniciaba el número de sus páginas con un breve artículo de presentación, escrito por nuestro padre que hizo de padrino periodístico en una prosa de saltarina gracia. Qué lástima el haber perdido aquellos preciosos párrafos que tanto releí entonces y en los que supo ser maestro de sus hijos".

Eduardo enriquece todavía más este singular y desconocido episodio de la biografía de Ortega contándonos el argumento del cuento que el filósofo preparó para aquella prematura experiencia editorial:

"Mi hermano José había escrito un a modo de cuento de sabor romántico, que despertaba fuerte y hermosa impresión. Describía una tarde otoñal en la que, las hojas secas, amarillas, eran arrastradas por el viento con un ruido característico. La tarde era anubarrada y la luz entre los árboles del Retiro madrileño era macilenta. Se oían las notas prolongadas de un violín que eran como un gemido musical. Pero no se veía al artista. En un instante pareció que se le divisaba, pero se esfumó su imagen. El lamento musical continuaba, a veces lejano, otras próximo y, un joven poseído de amor sin esperanza seguía, como las hojas secas, las notas del violín, tratando de alcanzar al artista. Aquellas notas eran la expresión de su amor y quería descifrarlas porque eran la revelación de su destino.

Tal era el trazo fundamental del argumento. Mas lo que tendría hoy valor para estudiar al artista naciente es su arte retórico espontáneo que era ya prodigioso. No lo había logrado sin trabajo. Sus primeros ensayos de niño luchaban con la dificultad del que perseguía un estilo personal, de una manera más o menos premeditada. Si se hubiera contentado con redactar sencillamente lo hubiera logrado sin esfuerzo. Pero «las ideas afluían a su torrentera interior con abundancia, borboteo y delicioso atropellamiento». Y en los dedos del niño querían florecer todas al mismo tiempo en el tallo de su pluma".

La actuación periodística de Ortega comenzó, como vemos, muy pronto, y no cesará hasta los años cuarenta. A los trabajos de Faro de Vigo y Vida Nueva siguieron otros dos publicados en 1903 en Helios, revista por antonomasia de la generación del 98, "la publicación más interesante de la nueva estética" (Mainer, 1983: 52). En estos primeros años de juventud lo encontramos, además, en La Lectura. Revista de ciencias y artes (1904), publicación de periodicidad mensual llena de sesudos y largos artículos; en Faro (1908), revista impulsada por el propio Ortega tras su vuelta de Alemania y sufragada, según su hermano Eduardo, por el tío Ramón Gasset (Redondo, 1970: 120); en Europa. Revista de cultura popular (1910), fundada por Luis Bello y saludada por Ortega desde las páginas de El Imparcial con estas emblemáticas palabras: "Hace poco tiempo apareció en los puestos de periódicos una nueva revista: Europa. 
El título no podía ser más agresivo: esa palabra sola equivale a la negación prolija de cuanto compone la España actual" (Ortega, 2004, I: 338).

En realidad, estas primeras colaboraciones en distintos medios fueron para Ortega breves ejercicios literarios paralelos a su auténtico desempeño profesional periodístico, que fueron, sin duda, las colaboraciones en uno de los rotativos más importantes del momento: El Imparcial, "la cumbre de la fama periodística", según la hermosa semblanza que Azorín dedicó al periódico en su Madrid. (Azorín, 1982: 862).

Muy pronto aparecen las primeras críticas de Ortega en el suplemento literario Los Lunes de El Imparcial: el 14 de marzo de 1904 publica "El poeta del misterio" y el 25 de julio de ese año encontramos "Alrededor de un libro. El rostro maravillado".

Podría creerse que para Ortega ascender a la cumbre periodística de El Imparcial fue un camino fácil; al fin y al cabo, el periódico era propiedad de su familia materna, los Gasset, y el director, su padre, el fino periodista José Ortega Munilla. No se puede negar que esta circunstancia natalicia tuvo algo que ver en el rápido éxito periodístico del joven filósofo, que ya en cierta ocasión, en un artículo de 1920, dijo de sí mismo que había nacido sobre una rotativa (Ortega, 2005, III: 345), y años después, en 1931, reconoció que era "periodista de toda la vida, mejor aún, de toda la vida de varias generaciones por uno y otro lado familiar" (Ortega, 2005, IV: 652). Ortega, que antropológicamente concebía al hombre como un "heredero", conocía este legado literario que el devenir biográfico familiar había depositado en él, a pesar de que Juan Marichal considere que "empezar a escribir en Madrid, hacia 1902, no fue para Ortega, pese a lo que él pretendía, empezar a llorar". Para este autor, "su queja dolorida, de adolescente que evoca la sombra de Larra, coexiste con el ímpetu gozoso del joven que se acerca a la vida, protegido por un ambiente familiar, con la íntima seguridad de que todo es posible". Vemos cómo Marichal considera que "el joven ensayista no tenía que esforzarse socialmente -otra cosa, claro está, era el intenso trabajo personal- para alcanzar la cumbre: en ella habitaba” (Marichal, 1984: 213).

Estas observaciones cargadas de sentido no nos deben llevar a la equivocación de que Ortega tuvo todas las puertas abiertas. De hecho, al principio tuvo que pelear para que su propio padre, convertido en severo censor, le publicara sus primeros artículos, muchos de los cuales quedaron inéditos. Si repasamos las Cartas de un joven español, que su hija Soledad Ortega publicó en 1991 para dar a conocer la correspondencia del joven intelectual durante su etapa de formación en Alemania, podremos matizar la citada "escalada hasta la cumbre".

Como quiera que la vida en Alemania era costosa, Ortega pidió en repetidas ocasiones a su padre que le publicara los artículos que le iba enviando para así reunir algún dinero que dulcificara la carestía de la estancia en el extranjero. En alguna ocasión, incluso, le llegó a solicitar que le nombrara corresponsal del periódico en Berlín: 
"Se me ha ocurrido una idea -escribe al padre el 15 de octubre de 1905-: ¿2Por qué no me nombras corresponsal del periódico en Berlín? Aunque los telegramas sólo hubieran de ser en casos excepcionales, una media columna un día sí y otro no de vida alemana, creo que sentaría bien al periódico: política, vida económica, corte, semblanzas, escenas, literatura de succés... Esto me supondría un trabajo de dos horas o dos horas y media cada jornada y merecería pagarse 300 francos (no creo que nadie pueda tener un corresponsal más barato en Berlín). Podía hacer una serie de interviews a sabios, escritores, etc. Desde que puedo leer alemán voy haciendo grandes progresos en la comprensión de este tinglado y espero estar al corriente dentro de poco" (Ortega, 1991: 197).

Observemos cómo el autor se ofrecía por cuatro duros para trabajar como corresponsal del periódico familiar y encima sin conseguirlo, no sólo la corresponsalía, sino tampoco la publicación de algunos artículos que el padre dejó en la oscuridad ${ }^{6}$. A este ofrecimiento como corresponsal habían precedido varias cartas acompañadas de sendos artículos que Ortega no consiguió colocar en El Imparcial. El 28 de marzo de 1905, escribía a sus padres:

"Dentro de pocos días recibiréis certificados unos cuantos artículos míos con destino a El Imparcial y Blanco y Negro. Ignoro si serán publicables. Mensualmente y con una pasmosa regularidad, recibiréis cuatro artículos de columna y media para Los Lunes que, si sirven, podían ser cobrados a 6 duros. Ídem tres articulitos para Blanco y Negro con su adjunta fotografía que serán cobrables a 6 duros. Ídem un artículo para La Lectura que será cobrable a 13 ó 15 duros. Pondré, como en estos que ahora envío, toda mi alma en ellos. Aun así, y suponiendo que sean utilizables me queda el resquemor de que estoy dudando si me conviene o no me con-

${ }^{6}$ De la lectura de otras cartas recogidas en el mismo volumen, se desprende que Ortega Munilla aceptó, en una ocasión, que Ortega actuara como corresponsal para cubrir el viaje del Rey a Alemania, pero debió ser un fracaso. En un primer momento leemos: "Querido padre: recibí anoche tus cartas anunciándome mi exaltación a corresponsal durante la estancia del Rey. Hoy espero tener las instrucciones detalladas y mañana me presentaré al embajador o acaso hoy mismo. Esto me obliga a comprarme ropa y hasta puede que necesite una chistera lo cual será muy desagradable" (3-11-1905). Sin embargo, esta emoción primera se transforma en desazón a los tres días: "Querido padre: estoy rendido. Para venir a un café a hacer esto he tardado no sé el tiempo. [...] Sólo estará aquí mañana [el Rey, se entiende]. De modo que si no me decís nada y no me envías fondos del periódico para ir, no podré hacer las cartas diarias. Lo de hoy es muy malo por falta material, de tiempo y de noticias" (6-11-1905). La siguiente carta contiene no pocas quejas por lo costoso que es el seguimiento informativo del Rey y la desazón que el trabajo de corresponsal parece provocar en Ortega: "Yo he hecho el tonto estos días y en una posición bastante ridícula. Como ya me había presentado en la Embajada, en calidad de corresponsal, no he tenido más remedio que asistir a todas las combinaciones que de allí dependían. Sólo por eso fui ayer. Lo que tengo sobre el alma son los coches que he pagado, y una chistera y unas botas de charol que para nada me volverán a servir. Enviaré recortes de la prensa alemana" (11-11-1905). Al día siguiente, en carta a su madre, protesta por el encargo de seguir el viaje del Rey: "Me ha fastidiado mucho por un sinfín de razones y sin ninguna satisfacción porque lo que me encargó papá era imposible hecho con seriedad: las ridiculeces del Heraldo y Correspondencia lo demuestran" (12-11-1905). Su madre debió contestarle que le habían gustado las crónicas sobre le viaje del Rey, porque Ortega le replica: "Lamento que os hayan parecido bien las notas de Berlín porque a mí me han parecido muy mal. Las he escrito en un café en medio de la conversación con otros españoles. [...] Hoy he recibido dinero, al parecer, del Periódico. Tengo un montón de cartas que contestar y mucho que estudiar. Por eso te dejo" (17-11-1905). Y así terminó su anecdótica labor de corresponsal. Parece claro que a Ortega le provocaba cierta antipatía el periodismo pero como oficio informativo, no como tribuna para intervenir en la vida pública. Sobre las profundas diferencias de Ortega con la profesión periodística diremos algunas palabras más adelante. 
viene publicar artículos por ahora. Un poco molesto es, en verdad, ser hombre de letras. Mas como no sé a punto fijo si me conviene o no, enviaré sin la menor falta esos 55 duros de artículos" (Ortega, 1991: 123-124) ${ }^{7}$.

Como vemos, el joven Ortega se tuvo que enfrentar a su padre, a veces con bastante acritud: "Dime si no te parecen bien mis notas y por qué, con objeto de mejorarme y enmendarme. Asuntos hay a sacos" (Ortega, 1991: 203), le rogaba en vista de que no aparecía publicada ni una sola de sus entregas. En la misma carta ya le había inquirido: "Quisiera, papá, con toda seriedad que se me organizara definitivamente, seguramente y moralmente algunos medios para vivir por y ante mí mismo" (Ortega, 1991: 201), en alusión a la concreción económica de su colaboración con el periódico.

De estos sinceros testimonios podemos deducir que, aun admitiendo que Ortega habitaba en la cumbre, tuvo que luchar para acomodarse en ella. Vicente Cacho Viu resume certeramente esta situación al asegurar que "el enfrentamiento generacional entre padre e hijo no fue más allá de los niveles habituales", y añade: "El talento de Pepe, aun dándose por supuesto, no sería objeto de ningún especial reconocimiento sobre sus hermanos: Ortega Munilla tardó años en aceptar sus puntos de vista novedosos y sometió a una férrea censura los escritos primerizos enviados por el hijo desde Alemania, que no siempre se publicaron; tampoco Pepe abdicó nunca ante el padre de su extrema exigencia crítica, recurriendo al subterfugio -tan normal- de exponer los puntos más conflictivos en las cartas a su madre, una mujer delicada y piadosa, según podía esperarse de su tiempo y clase, ajena por completo a los pleitos que se traían los varones de la familia”. En resumen, Cacho zanja la cuestión asegurando que "Ortega no fue el niño mimado de un clan influyente en la escena pública española, aunque su talento supiera sacar partido de la plataforma, tampoco despreciable, de la que partía en la vida" (Cacho Viu, 1991: 19-20).

\section{Grandes proyectos periodísticos para un periodismo combativo}

De los orígenes de la actuación periodística de Ortega nos queda la evidencia de que El Imparcial fue el gran medio de comunicación que permitió al intelectual llegar al gran público y darse a conocer desde muy joven. Reparemos en que cuando irrumpe en la vida pública española lo hace con compañeros de pluma ya consagrados como Galdós, Baroja, Azorín, Valle, Mariano de Cavia...

Ortega escribirá en El Imparcial hasta 1917, cuando la publicación de su famoso artículo "Bajo el arco en ruina" (11 de junio de 1917; cfr. Ortega 2005, IV: 751-754), le enfrenta sin solución con los principios fundacionales de respeto al orden social y político constituidos y consagrados por la empresa, lo que le acarrea su ruptura de relaciones con el diario familiar.

\footnotetext{
${ }^{7}$ En la nueva edición de las Obras completas, concretamente en el tomo I, se pueden leer las crónicas y artículos que Ortega consiguió publicar en El Imparcial durante su estancia en Alemania entre 1905 y 1906, que corresponden a las series de tituladas "Notas de Alemania", "Notas de Berlín", "La Universidad española y la Universidad alemana" y "La ciencia romántica”. Estos artículos, además de los que su padre dejó inéditos, también están publicados en Cartas de un joven español, pp. 686 y ss.
} 
El intelectual ya había tenido que refugiarse alguna vez en otros medios izquierdistas para exponer su doctrina política: en 1910 lo podemos leer en El Radical, periódico republicano fundado por Lerroux; entre 1913 y 1914, Ortega colabora con El País, también republicano, con tres artículos; además, el Primero de Mayo de 1913, con motivo de la festividad del trabajo, publica un artículo titulado "Socialismo y aristocracia” en El Socialista, órgano propagandístico del PSOE. Ortega era consciente de que en su "casa solariega", como alguna vez se refirió a El Imparcial, no podía decir lo que quisiera.

Como es sabido, estos años Ortega propugna la involución total del régimen monárquico, lo que se comprende muy bien con la metáfora del "arco en ruinas": España vive bajo el arco ruinoso de un sistema caciquil que impide, entre otras cosas, la educación popular, basamento de un país. Ortega cree, muy en sintonía con los ilustrados y regeneracionistas, que la única prosperidad para España se logra mejorando el nivel cultural de los españoles, pero para ello hace falta despojar del poder político a los caciques, interesados en mantener una población sumisa y analfabeta; como los caciques están amparados por el rey, a quien hay que eliminar del sistema es al propio rey. Todo arco tiene su piedra angular gracias a la cual se sostienen las demás; si el rey, o sea la monarquía, es la piedra angular de este arco en ruinas que es España, quitemos la monarquía para que sucumba el arco ruinoso y se pueda edificar uno nuevo.

Evidentemente, esta doctrina no la podía plantear en el rotativo conservador y monárquico que era El Imparcial, y al hacerlo, Ortega sabía a lo que se exponía ${ }^{8}$. No obstante, el periodismo combativo político no sólo es desempeñado por Ortega desde El Imparcial o, eventualmente, desde la prensa republicana. En 1915 encontramos al pensador madrileño enfrascado en su primer gran proyecto periodístico: la revista España. Semanario de la vida nacional. Comprender por qué Ortega funda este semanario implica comprender su biografía alrededor del crucial año de 1914, y por extensión, sus postulados doctrinales en materia política y social ${ }^{9}$.

En el primer número de la publicación (29 de enero de 1915) Ortega escribe el editorial titulado “España saluda al lector y dice:", del que me parece conveniente extractar algunas líneas:

“Nacido del enojo y la esperanza, pareja española, sale al mundo este semanario: España.

${ }^{8}$ Para conocer con detalle la salida de Ortega de El Imparcial se pueden leer las páginas que Gonzalo Redondo dedica al suceso en el tomo I de Las empresas políticas de José Ortega y Gasset, Madrid: Rialp, 1970. Aquí se explica cómo "Bajo el arco en ruina" no sólo provocó la salida de Ortega sino que también frustró la compra del periódico que Nicolás María de Urgoiti tenía casi cerrada con los Gasset. La consecuencia fue que el intelectual y el empresario vasco se aliaron para fundar juntos El Sol, que nació en diciembre de 1917.

${ }^{9}$ No tenemos espacio para recrear la historia de esta importante revista española, pero si el lector quiere conocer más de ella, además de las referencias que hallará en los manuales de Historia del Periodismo debe consultar las cartas que José Ortega Munilla envió a su hijo en contestación a las tribulaciones que Ortega debía estar pasando para sacar adelante el proyecto. Están publicadas en Revista de Occidente, 3. ${ }^{a}$ época, n. ${ }^{\circ}$ 193, mayo de 1997, número en el que también encontrará un interesante artículo de Juan Francisco Fuentes titulado "España: olvido y vigencia de una empresa orteguiana". 
[...] Tú, lector, que tal vez vives en el fondo de una provincia, ocupado en la modestia de tus afanes aldeanos, recapacita con la mano puesta sobre el corazón y pregúntate qué institución vigente de la vida pública española te merece confianza y te impone respeto. $i$ No es cierto que del Parlamento a la Universidad, pasando por las Academias, del Ministerio de la Guerra a los Cuerpos judiciales, pasando por las oficinas de Hacienda, nada despierta en ti fe? El desprestigio radical de todos los aparatos de la vida pública es el hecho soberano, el hecho máximo que envuelve nuestra existencia cotidiana. Todos sentimos que esa España oficial dentro de la cual o bajo la cual vivimos, no es la España nuestra, sino una España de alucinación y de inepcia.

[...] Es preciso reorganizar la esperanza española. Mientras no entren en erupción pasional e intelectual los últimos rincones peninsulares, mientras cada español no posea la voluntad y la orgullosa dignidad de sí mismo, mientras no logre hacer que se respeten sus deseos y empeños particulares, mientras la palabra «ministro» signifique otra cosa que servidor y la palabra «diputado» otra cosa que mandadero -que es su estricto sentido-, no podrá comenzar la restauración de nuestra raza.

[...] Nuestra política será, pues, la más sencilla del mundo: en toda ocasión, en todo momento estaremos al lado de la España humilde de las villas, los campos y las costas, frente a las instituciones carcomidas; nos haremos solidarios de toda intención noble, de toda persona benemérita, de toda queja justa, cualquiera que sea su origen y su nombre.

[...] Entre los españoles que piensan así, no creemos ser nosotros ni los mejores ni los primeros. Somos unos de tantos que ofrecemos a los demás en estas columnas un cauce limpio donde puedan fluir los raudales de su nuevo patriotismo. Se publica en Madrid nuestro semanario, pero será escrito en toda la nación. No es para nosotros Madrid el centro moral del país. Por cada pueblo, por cada campiña pasa, a cierta hora del año, el eje nacional. Solicitamos, pues -sin ella nada haríamos-, la colaboración de cuantos aspiran a una España mejor y creen que a ella se llega mediante una rebeldía constructora.

¡Lector, te pedimos para España diez céntimos y todo lo demás para España!” (Ortega, 2004, I: 829-830).

No hace falta seguir transcribiendo este primer editorial de la revista para comprender su carta de naturaleza. Basta con que reparemos en que Ortega apela a la "rebeldía constructora" para terminar con la "España de alucinación y de inepcia" que encarnan los ministros y diputados, y para esta "reorganización de la esperanza española", para esta "restauración de nuestra raza", hace un llamamiento a todo español "benemérito" que no se sienta parte de la "España oficial". He aquí su programa político hacia 1915, programa fundamentado en la conferencia "Vieja y nueva política" que Ortega había pronunciado un año antes, el 23 de marzo de 1914, en el Teatro de la Comedia de Madrid (cfr. Ortega, 2004, I: 710-737). También de esta fecha es otra iniciativa orteguiana, la creación de la "Liga de Educación Política Española”, suerte de agrupación de intelectuales decididos a recorrer España para aplicar lo que tantas veces Ortega propugnó: la pedagogía social como programa político.

Por lo tanto, hemos llegado a la primera conclusión de que los proyectos periodísticos de Ortega no pueden ser estudiados aisladamente, como meras empresas de comunicación, sin tener en cuenta este marco doctrinal de referencia que les da sentido, coherencia y unidad. La revista España, como antes Faro (con su metafórico nombre de guía o indicador en la tempestad), muy pronto El Sol (1917), 
con su no menor resonancia de luminiscencia y claridad, después Revista de Occidente (1923) y, finalmente Crisol y Luz (1931) son todos proyectos periodísticos filiados a la misma raigambre doctrinal: la necesidad que siente Ortega de intervenir en la sociedad española para acrecentar su nivel cultural, para provocar que "cada español se resuelva a elevar unas cuantas atmósferas la presión de sus potencias espirituales” (Ortega, 2005, III: 21). A esta mejora de la inteligencia colectiva orienta Ortega sus empresas periodísticas. Dicho de una sola vez, el autor asume el periodismo como un sacerdocio, de ahí que desarrolle en cada uno de estos medios un periodismo combativo, militante, puesto al servicio de esta noble causa: el enriquecimiento de la educación y del acervo populares.

Ahora se ve claro que el nacimiento de $E l$ Sol en diciembre de 1917 culmina la frenética actividad periodística de Ortega durante la primera mitad de su vida (para entonces cuenta 34 años). Sólo con esta perspectiva de su trayectoria periodística se comprende la ideación de un gran periódico a la europea, colmado de información procedente del ancho mundo, cargado de doctrina y pensamiento como fue El Sol.

"Por vez primera aparece mi nombre semioscuro en este periódico, cuyas columnas espero frecuentar. Ya que no pueda otra cosa, quisiera verter en sus moldes mis esperanzas españolas. Lector, he de hablarte a menudo desde $E l$ Sol sobre cosas de la tierra, especialmente sobre cosas políticas de la tierra, y más especialmente todavía sobre cosas políticas de la tierra de España.

El título de este periódico significa, ante todo, un deseo de ver las cosas claras. Frente a cualquier hecho o problema equivale, pues, a un imperativo de mayor claridad y a una apelación que del crepúsculo hacemos al mediodía" (Ortega, 2005, III: 21).

Así arrancaba el primer artículo que Ortega publica en El Sol el 7 de diciembre de 1917, "El hombre de la calle escribe...", que inauguraba la serie titulada "Hacia una mejor política". La declaración es tajante: el autor se va a ocupar de asuntos de política con la voluntad de claridad como principio motor. Efectivamente, la actividad periodística de Ortega en $\mathrm{El} \mathrm{Sol}$ se cierne, principalmente, sobre las cuestiones relacionadas con la política, y lo hará por medio de estos dos géneros: el editorial y el artículo político (que en el caso de Ortega es de dos tipos: de actualidad política y de doctrina política) ${ }^{10}$.

Es imposible detenerse más tiempo a narrar las peripecias de Ortega en El Sol, aunque sí es bueno que el lector sepa que su salida del periódico se debió a sucesos bastante similares a los ocurridos en El Imparcial. Hacia 1930, inminentes las elecciones municipales de 1931 que trajeron la II República a España, el consejo de administración del periódico de Urgoiti se opuso a la línea editorial defendida por

${ }^{10}$ He clasificado y analizado los distintos géneros periodísticos cultivados por Ortega en El periodismo de José Ortega y Gasset, Madrid: Biblioteca Nueva, 2005. En concreto, el estudio de sus artículos políticos se encuentra entre las pp. 15-60, y el de sus editoriales, entre las pp. 61-100. El resto de géneros tratados son el artículo filosófico, la crítica literaria, la crónica de viajes y la necrológica. 
su ideólogo máximo, que era Ortega, quien por esas fechas insistía exactamente en la misma denuncia de 1917 cuando publicó "Bajo el arco en ruina". Para Ortega, el sistema monárquico nacido de la Restauración Borbónica -que todavía pervivía en España-, seguía siendo la piedra angular del arco ruinoso. Esta tesis inspiró su conocido artículo "El error Berenguer", publicado en El Sol el 15 de noviembre de 1930, artículo en el que, tras una meticulosa disección de los problemas históricos y estructurales que lastraban a España, terminaba con la lapidaria sentencia de que la Monarquía estaba destruida.

“[...] Y como es irremediablemente un error, somos nosotros, y no el Régimen mismo; nosotros, gente de la calle, de tres al cuarto y nada revolucionarios, quienes tenemos que decir a nuestros conciudadanos: ¡Españoles, vuestro Estado no existe! ¡Reconstruidlo!

Delenda est Monarchia" (Ortega, 2005, IV: 764).

Cronológicamente hemos llegado a un momento interesante en esta suerte de biografía periodística del filósofo. Se comprende que la puesta en marcha de El Sol junto con el empresario vasco Nicolás María de Urgoiti, dueño de la Papelera Española, no es más que el desenlace natural de la trayectoria vital previa. Pero hemos dejado sin mencionar, deliberadamente, dos cuestiones importantes: por un lado, la idea de Europa en el entramado doctrinal orteguiano; por otro lado, la puesta en marcha de uno de los proyectos editoriales más emblemáticos de Ortega, la revista unipersonal El Espectador, nacida en 1916. Con el desarrollo de estos dos puntos completaremos esta aproximación al periodismo en la obra de Ortega y Gasset.

\section{"Aristócrata en la plazuela"}

Lo que todavía no sospecha el lector es que al tratar la idea de Europa en el universo de conceptos que iluminan el ideario político-filosófico de Ortega, caeremos "como por un escotillón" (expresión muy orteguiana), en el núcleo de su vocación periodística. Es decir, que siguiendo la ruta europea vamos a desembocar en la auténtica razón que impulsó al filósofo a dirigir sus esfuerzos hacia esa forma de "espiritualidad ínfima” que es el periodismo.

La expresión "espiritualidad ínfima” aplicada al periodismo pertenece al propio Ortega, quien, como ya he insinuado, mantenía profundas diferencias con la profesión periodística. Muchas veces en su obra arremete el filósofo contra "mis compañeros de profesión", a quienes reprocha "su falta de perspectiva", de "¡arquitectura!" para "fijar la atención en el asunto o asuntos que son lo más importante en cada etapa” (Ortega, 2005, III: 784). Para Ortega, "la interpretación periodística es y será siempre la perspectiva de lo momentáneo como tal. Por mucho que colaboren en el periódico los universitarios, la perspectiva, tono, tendencias y modos dominantes serán los periodísticos". El autor pone el énfasis en la diferencia entre la perspectiva universitaria de abordar la realidad y la perspectiva periodística: "La interpretación universitaria de las cosas es y será siempre la de acentuar en la actualidad lo no momentáneo" (Ortega, 2005, III: 346), en contra del presupuesto anterior. 
Estas explicaciones fueron dadas por Ortega a raíz de la polémica que suscitó la serie de artículos "Misión de la Universidad", publicada en 1930 en El Sol (que después se ha reeditado como un librito de los más breves y sugerentes del pensamiento orteguiano). En dicha serie, y siguiendo las teorías de Comte, Ortega aludía al rango de los "poderes espirituales" que influyen en la sociedad en cada época. Entre estos poderes o "realidades espirituales" se encuentran la Prensa y, claro está, también la Universidad. Pero para el autor, "la conciencia pública no recibe hoy otra presión y otro mando que los que le llegan de esta espiritualidad ínfima rezumada por las columnas del periódico. Tan ínfima es a menudo, que casi no llega a ser espiritualidad; que en cierto modo es antiespiritualidad" (Ortega, 2005, III: 567). Reclamaba, asimismo, no que el periódico dejara de ser un poder social, sino que no fuera el más importante, de modo que el lugar predominante que la prensa ostentaba fuera ocupado por la Universidad, realidad espiritual que, según Ortega, sí debía reunir las cualidades de poder rector.

Las profundas diferencias de Ortega con la prensa y con los modos periodísticos de tratar y comprender la realidad no implican que el autor no estuviera persuadido de lo necesario que es para la sociedad -para cualquier sociedad en general, pero para la española en particular-, una prensa fuerte, libre e independiente. De hecho, todo lo que hemos relatado hasta aquí nos ofrece la imagen de un promotor periodístico, de un visionario embarcado permanentemente en proyectos culturales de este orden. En 1920, contestando una Real Orden promulgada por el presidente Eduardo Dato que afectaba a la libertad industrial periodística, escribió este revelador párrafo:

"Aunque soy muy poco periodista, nací sobre una rotativa. Tal vez por este género de natividad me he sentido impulsado a desplazar algún esfuerzo hacia esta forma de labor literaria. Hace bastantes años fundé con el señor Rengifo, una revista semanal: Faro; luego, la revista España; más tarde colaboré en la fundación de $E l$ Sol. Con alguna hipérbole, pero dentro del sentido literal que el vocablo posee, puedo, en consecuencia, aspirar a que el añalejo me conmemore bajo el título de fundador. Resuelto por otra parte a no ser mártir, pienso en que mañana me ocurra fundar alguna otra publicación” (Ortega, 2005, III: 345).

De hecho, fundó a los tres años otra gran empresa periodística: Revista de Occidente, y aún quedaría su implicación en el nacimiento de Crisol y de $L u z$, ya con la República nacida.

Debe quedar claro que la cuestión no consiste en si Ortega creía o no en la utilidad social del periodismo; ya hemos dicho que admitía la eficacia de la prensa como poder social, y en el caso particular de España, como única realidad espiritual capaz de penetrar la epidermis popular. Esta convicción está expresada en varios lugares de la obra del pensador, pero yo creo que en ninguno como en el Prólogo para alemanes.

Este texto fue escrito por Ortega en 1934 para prologar una traducción al alemán de sus obras, pero quedó inédito porque el autor prohibió su publicación tras los terribles sucesos de Munich de ese mismo año. Se editó por primera vez en 1958 (Madrid: Taurus), y resulta un texto sumamente interesante pues se trata del único escrito de carácter autobiográfico que hallamos en la vasta obra del pensador. Entre 
las muchas ideas que ofrece al lector alemán (en quien pensaba cuando lo redactó), hay una que resulta medular para comprender el periodismo en la obra de Ortega:

“[...] De mis estudios en Marburg, en Leipzig, en Berlín, saqué la consecuencia de que yo debía por lo pronto y durante muchos años... escribir artículos de periódico" (Ortega, 1983, VIII: 21) ${ }^{11}$.

La frase sacada de contexto acaso se interprete como una ironía de Ortega, pero de eso no tiene nada. De hecho, se comprende perfectamente en el discurso que el autor está dirigiendo al público alemán:

“En aquella mi mocedad apasionada era yo, en efecto, un poco ese gavilán joven que habitaba en la ruina del castillo español. Me sentía no ave de jaula, sino fiero volátil de blasón: como el gavilán, era voraz, altivo, bélico, y como él manejaba la pluma. La cosa era, pues, muy sencilla. Yo iba a Alemania para traerme al rincón de la ruina la cultura alemana y allí devorarla. España necesitaba de Alemania. Yo sentía mi ser de tal modo identificado con mi nación, que sus necesidades eran mis apetitos, mis hambres" (Ortega, 1983, VIII: 24).

Ya se va vislumbrando por qué hemos tomado la ruta europea para llegar al centro gravitatorio de este artículo. Cuando Ortega afirma que "España es el problema y Europa la solución” se refiere justamente al nivel cultural europeo, a la ciencia alemana en concreto, que es lo que mejor conoce desde su juventud. Antes dijimos que la doctrina política propugnada por Ortega en las distintas empresas periodísticas a las que estuvo vinculado consistía, fundamentalmente, en el fomento del acervo popular español, "de cada español", de ahí la consigna "la pedagogía social como programa político", y de ahí la praxis política inmediata de darle la vuelta a la forma del Estado y prescindir de la inepta clase política. La experiencia europea para Ortega (como antes para los ilustrados que viajaron a países más desarrollados que España, $v$. g. Moratín: no hay más que leer sus crónicas viajeras por la paupérrima Andalucía tras su vuelta de Inglaterra), suponía sentir a España como "dolor"12. Ortega se compara con el gavilán que se trae la ciencia alemana al "rincón de la ruina" que era su patria, para aquí devorarla. Bien, ¿hemos reparado en lo que se propone Ortega con esta acumulación de sabiduría? Nos lo ha dicho ya: su formación en las principales universidades alemanas le sirvieron para comprender que durante mucho tiempo tendría que dedicarse a escribir artículos de periódico. Pero, ¿en qué consiste exactamente esta toma de conciencia? La respuesta la encontramos en su conocida metáfora del "aristócrata en la plazuela":

${ }^{11}$ El Prólogo para alemanes lo cito por la edición de 1983 de las Obras completas (Madrid: Alianza Editorial - Revista de Occidente, VIII, pp. 12-58), pues al tratarse de un escrito póstumo, se ubicará en el tomo IX de la nueva edición de las Obras completas, de las que sólo han aparecido cinco volúmenes hasta la fecha.

${ }_{12}$ Dolores Franco, esposa del recién fallecido Julián Marías, publicó un delicioso ensayo titulado España como preocupación, en el que rescata de entre la literatura nacional aquellas obras y autores que se han ocupado del sufrimiento que les han producido las desdichas de su patria española. Cfr. Franco, Dolores: España como preocupación, Barcelona: Argos Vergara, 1980. 
"Hacia ese señorío de la luz sobre sí mismo y su contorno quería movilizar yo a mis compatriotas. Sólo en él tengo fe; sólo él realzará la calidad del español y le curará de ese sonambulismo dentro del cual va caminando siglos hace.

Pero esta propaganda de entusiasmo por la luz mental -el lumen naturale- había que hacerla en España según su circunstancia impusiera. En nuestro país, ni la cátedra ni el libro tenían eficiencia social. Nuestro pueblo no admite lo distanciado y solemne. Reina en él puramente lo cotidiano y vulgar. Quien quiera crear algo -y toda creación es aristocracia- tiene que aceptar ser aristócrata en la plazuela. He aquí por qué, dócil a la circunstancia, he hecho que mi obra brote en la plazuela intelectual que es el periódico. No es necesario decir que se me ha censurado constantemente por ello. Pero algún acierto debía haber en tal resolución cuando de esos artículos de periódico han hecho libros formales las imprentas extranjeras" (Ortega, 1983, VI: 352-353).

Ahora se comprende en su completitud la actuación periodística de Ortega, o por lo menos su vocación hacia "esta forma de labor literaria". No hay otro camino para llegar al español medio que a través de los periódicos, porque lo solemne y distanciado como formas de comunicación están condenados al fracaso, al menos con este pueblo.

"El artículo es hoy una forma imprescindible del espíritu, y quien pedantescamente lo desdeña no tiene la más remota idea de lo que está aconteciendo en los senos de la historia" (Ortega, 1983, VI: 354).

Es importante subrayar este aspecto: Ortega jamás olvida a qué lector se dirige, quién es ese individuo a quien se propone conducir "hacia el señorío de la luz". "Una idea es un poco estúpida si el que la dice no cuenta al decirla con quien es aquel a quien se dice" (Ortega, 1983, VIII: 17). "Yo hablaba a Juan", confiesa magistralmente en el Prólogo para alemanes, "contando con Juan y contando con que Juan sabe quién le habla". Es decir, cada español medio llamado hoy a ser más inteligente que ayer ha sido "Juan" para Ortega en toda su obra. Con él ha hablado sobre la circunstancia española y a él le ha hablado de la necesidad de orientar los esfuerzos íntimos hacia el señorío de la luz que representan la ciencia, la universidad, la aristocracia intelectual, que es la aristocracia nacida de la nobleza interior, del amor intellectualis, del querer acercarse a las cosas para comprenderlas en su justa medida y amarlas como son.

De todo ello se deduce que el periodismo fue para Ortega ese estilo con el que lograba comunicarse con Juan: "La involución del libro hacia el diálogo: éste ha sido mi propósito", confiesa en su texto autobiográfico.

"Si el lector analiza lo que ha podido complacerle de mi obra, hallará que consiste simplemente en que yo estoy presente en cada uno de mis párrafos, con el timbre de mi voz, gesticulando, y que, si pone el dedo sobre cualquiera de mis páginas, se siente el latido de mi corazón.

[...] Todo proviene de que en mis escritos pongo, en la medida de lo posible, al lector, que cuento con él, que le hago sentir cómo me es presente, cómo me interesa en su concreta y angustiada y desorientada humanidad. Percibe como si de entre las líneas saliese una mano ectoplásmica pero auténtica, que palpa su persona, que quiere acariciarla -o bien, darle, muy cortésmente, un puñetazo" (Ortega, 1983, VIII: 17-18). 


\section{Hacia un periodismo contemplativo: El Espectador}

Al estudiar en su conjunto la producción periodística de Ortega y Gasset parece que después de 1914 y, sobre todo desde 1916, algo ha cambiado, que la apariencia de los textos anteriores y su mensaje subterráneo han sufrido una ligera mutación. Hasta ahora nos hemos encontrado con un Ortega que asume su destino vital, o sea, la misión de "restaurar la raza española"; de ahí su frase: yo tenía que escribir artículos de periódico, donde tener que delataba la asunción de dicho destino.

Sin embargo, como decimos, algo ha cambiado a la altura de 1916. Por un lado, Ortega abandona en poco menos de un año su proyecto editorial de la revista España. Por otro lado, la piedra angular de su programa de regeneración española, Europa, sucumbe ante la magnitud de la Gran Guerra. El ideal europeo se desmorona; Europa se tambalea como solución; Europa se ha vuelto el problema; Europa, como horizonte diáfano, se difumina y ahora sólo proyecta muerte, pesadumbre, destrucción.

Sin esta circunstancia no se puede comprender al Ortega posterior a 1914. Pero, además de esta causa exógena (la Gran Guerra), aún podemos aducir otra razón endógena al propio pensador que nos ayudará a clarificar la evolución que describimos. En 1913 Ortega cumple 30 años. Se produce un salto generacional, su evolución de la juventud a la madurez:

"Mi mocedad no ha sido mía, ha sido de mi raza. Mi juventud se ha quemado entera, como la retama mosaica, al borde del camino que España lleva por la historia. Hoy puedo decirlo con orgullo y con verdad. Esos mis diez años jóvenes son místicas trojes henchidas sólo de angustias y esperanzas españolas" (Ortega, 2004, II: 9).

Reparemos en que en este fragmento del prólogo a Personas, obras, cosas (1916) Ortega habla en pasado de su mocedad, es decir, que fija en sus 30 años el cambio de un estado vital a otro, momento que coincide con la aparición del primer volumen de El Espectador. Si alguien deseara conocer al Ortega maduro no tendría más remedio que acudir a las páginas de El Espectador, como no tendría más remedio que aprenderse "Vieja y nueva política" para comprender al Ortega joven.

El Espectador es una obra sencillamente deliciosa, sobre todo desde el punto de vista literario. Se trata de un singular proyecto unipersonal que el autor se propone publicar periódicamente; es una suerte de revista con forma de libro que da acogida a diversos géneros periodísticos, con la excepción deliberada del articulismo político. En la primera página del primer volumen, en el artículo titulado "Verdad y perspectiva", se nos explica que no es que el autor desdeñe la política como instrumento de intervención en la vida social española. Lo que ocurre es que ha llegado un momento en que Ortega necesita algo más que acción política; intelectualmente precisa de un espacio donde verter los frutos de una acción contemplativa del mundo alejada del utilitarismo político, utilitarismo perjudicial para la acción pensante del intelectual.

Desde las páginas de El Espectador, Ortega se propone una obra diferente a la acción política porque intelectualmente necesita "acotar una parte de sí para la contemplación”. La dicotomía acción políti- 
ca-acción contemplativa consiste en que la política está situada "en un rango de actividad espiritual secundaria", porque "cuando la política se entroniza en la conciencia y preside toda nuestra vida mental, se convierte en un morbo gravísimo” (Ortega, 2004, II: 159). Este morbo gravísimo consiste en que la utilidad del pensamiento político impide buscar la verdad de las cosas. Para Ortega, la política es la supeditación de la teoría a la utilidad, por eso, "si esta preocupación por lo útil llega a constituir el hábito central de nuestra personalidad, cuando se trate de buscar lo verdadero tenderemos a confundirlo con lo útil. Y esto, hacer de la utilidad la verdad, es la definición de la mentira" (Ortega, 2004, II: 159-160).

Según este argumento, comenzamos a vislumbrar en el autor no ya una decisión por dedicarse a otra actividad diferente y opuesta del periodismo político-militante, sino más aún, percibimos desazón y cansancio. Ortega necesita huir de ella y encaminarse hacia otro estadio donde pueda hablar de la verdad: "Congoja de ahogo siento", escribe en 1916. "No he hallado en derredor sino políticos, gentes a quienes no interesa ver el mundo como él es, dispuestas sólo a usar de las cosas como les conviene" (Ortega, 2004, II: 160).

Ya hemos llegado a la espina dorsal del nuevo proyecto periodístico: “El Espectador tiene, en consecuencia, una primera intención: elevar un reducto contra la política para mí y para los que compartan mi voluntad de pura visión, de teoría” (Ortega, 2004, II: 160).

José Lasaga relaciona esta cualidad antipolítica de El Espectador con la periodicidad tan irregular de la revista: "Es difícil establecer una hipótesis", sostiene Lasaga: "Es posible que guarde relación con otras actividades a las que tenía que atender Ortega, señaladamente la académica y la política. Pero puesto que publicó ensayos elaborados con investigaciones y cursos de la cátedra, es la política lo que da la clave de las fechas de aparición de los distintos espectadores: coinciden con los años de mínima actividad política de Ortega" (Lasaga, 1998: 233-243).

Al desechar el pensar utilitario como principio, Ortega se ocupará en la revista de múltiples temas: libros y lecturas (Azorín, Baroja...), arte (en muchas de sus manifestaciones como la música -“Musicalia"-, la pintura, la arquitectura), filosofía (“Las dos grandes metáforas", "Hegel y América”...), sociología, antropología, biología, pedagogía... y los viajes, los viajes como una de las grandes aportaciones del autor a este género periodístico: "Tierras de Castilla"; "De Madrid a Asturias o los dos paisajes"; "Notas de vago estío" -en las que recorre el norte peninsular; "Cuaderno de bitácora” -donde se incluyen las páginas dedicadas a "la profundidad de Francia", etcétera.

Otros rasgos que debemos considerar de El Espectador son el público al que se dirige, el nombre de la publicación, su carácter unipersonal y la periodicidad. De la singularidad de su público da cuenta el que no se respetaran periodos determinados ni fechas exactas de lanzamiento, aunque al principio 
Ortega se comprometiera a publicar un número de 200 páginas cada dos meses ${ }^{13}$. Por otra parte, hay varios antecedentes notorios al título de la revista: en el extranjero, ya se habían publicado varios "espectadores", como The Spectator, de Adisson, que aparece diariamente desde el primero de mayo de 1711 hasta el 16 de diciembre de 1712, o el Spectateur française, en 1725, escrito y publicado por Marivaux. Estos dos como antecedentes remotos porque, coetáneo de El Espectador orteguiano fue el Spectator londinense, "revista sociológica y literaria que aparece los sábados en casa de los señores Smith \& Son” (Saldaña, 1916: 184).

En cuanto a la condición de revista unipersonal, también en España hay antecedentes de este tipo de publicaciones, al menos dos según Saldaña: "Revistas personales tuvieron entre nosotros Balmes y Concepción Arenal, pero se arguye que eso fue en época de escasa y difícil publicidad periódica" (Saldaña, 1916: 197).

Ortega describió su proyecto de este modo:

"Es una obra íntima para lectores de intimidad, que no aspira ni desea el «gran público», que debería, en rigor, aparecer manuscrita. En estas páginas, ideas, teorías y comentarios se presentan con el carácter de peripecias y aventuras personales del autor" (Ortega, 2004, II: 155).

El Espectador busca espacios abiertos, y esto hay que tomarlo, al menos, en dos sentidos: temático y formal. Fijémonos en la advertencia de Ortega cuando se dirige por primera vez a sus suscriptores:

“Debe el lector entrar en la lectura sin altas esperanzas. Yo no sé hasta cuándo ni en qué grado de plenitud podré llevar adelante el empeño. El tiempo, tan galantuomo, se encargará de decírnoslo a los lectores y a mí.

[...] Habrá números que padezcan aridez mental. El escritor pasa, a lo mejor, por zonas espirituales donde no brota una idea. A veces, dura meses la estéril situación. Durante ellas el lector habrá de contentarse con un «espectador» que lee, extracta y copia. Otros números llevarán un trozo de mi alma” (Ortega, 2004, II: 155).

\section{Y continúa:}

"Es El Espectador la conmovida apelación a un público de amigos de mirar, de lectores a quienes interesen las cosas aparte de sus consecuencias, cualesquiera que ellas sean, morales inclusive. Lectores meditabundos, que se complazcan en perseguir la fisonomía de los objetos en toda su delicada, compleja estructura. Lectores sin prisa, advertidos de que toda opinión justa es larga de expresar. Lectores que al leer repiensen por sí mismos los temas sobre que han leído. Lectores que no exijan ser convencidos, pero, a la vez, se hallen dispuestos a renacer en toda hora de un credo habitual a un credo insólito. Lectores que, como el autor, se hayan reservado un trozo de alma antipolítico. En suma: lectores incapaces de oír un sermón, de apasionarse en un mitin y juzgar de personas y cosas en una tertulia de café.

\footnotetext{
${ }^{13}$ Así se anuncia en España el 20 de enero de 1916, p. 8.
} 
A hombres y mujeres de tan rara índole se dirige El Espectador, que es un libro escrito en voz baja" (Ortega, 2004, II: 161).

En definitiva, El Espectador fue para Ortega, en medio de la agotadora jornada que le imponía la publicación diaria sobre asuntos políticos, un oasis en el que desembarazarse de la presión y la tensión periodísticas.

\section{Balance final}

La naturaleza descriptiva de este artículo nos ha evitado la valoración de ciertas cuestiones sinuosas, como la descrita en el epígrafe del periodismo combativo. Reparemos en que sería un error de perspectiva evaluar la prensa de entonces con los actuales criterios profesionales, aunque es posible que, aun habiéndose profesionalizado el periodismo, todavía hoy podamos seguir hablando de prensa militante, combativa, de prensa de partido o de "periodismo ideológico", que es como denomina Ángel Benito al periodismo de principios del siglo XX, más concretamente al que se desarrolla antes de la Primera Guerra Mundial (Benito, 1982: 74-75). Efectivamente, aquélla fue una prensa proselitista, puesta al servicio de las causas políticas, religiosas... hasta el punto de que algunos autores atribuyen la llegada de la República a la influencia de periódicos como El Sol:

\footnotetext{
"Durante los diecinueve años de su existencia, fue $E l$ Sol uno de los mejores periódicos de Europa y, desde luego, el mejor de España de todos los tiempos. Órgano y tribuna de una sola política nacional de signo moderno, ejercía fuerte presión sobre el espíritu público, hasta el punto de haberse dicho que «fueron los editoriales de El Sol los que trajeron la República española»" (Espina, 1993: 250-251).

La opinión es compartida por otros testigos como Luis Calvo, director de $A b c$ durante el Franquismo:

"Yo tengo la creencia de que la República no hubiera venido si Ortega, Pérez de Ayala y Marañón no hubieran creado la Agrupación al Servicio de la República. Seguro. La trajeron por la influencia intelectual tan asombrosa que ejercían desde las páginas de $E l \mathrm{Sol}$. El periódico llegaba hasta las manos del intelectual de cada pueblo, de cada capital de provincia, que eran los que verdaderamente influían sobre los demás. Y estos intelectuales -el médico, el boticario, el maestro de cada lugar- vivían deslumbrados por el prestigio de estas tres figuras, y claro, votaron a la República con ellos” (Berasátegui, 1987: 262-269).
}

Los teóricos de la comunicación son quienes mejor conocen las dificultades para calcular la influencia real de un medio de comunicación, su calado en el tejido social, la cuota de responsabilidad atribuible a un periódico o grupo de comunicación de acuerdo con el comportamiento de los individuos. Espina y Calvo están en la creencia de que El Sol determinó el advenimiento de la II República, pero, como diría Ortega, "en las creencias se está", del mismo modo que se puede dejar de estar. Hubo un autor, Vicente Romano, que en los años setenta defendió una tesis doctoral en la que trataba de evaluar si la labor "publicística" de Ortega fue exitosa o no, y para ello tomó los hechos políticos hasta la España republicana y los contrastó con la intervención pública de Ortega. Su conclusión es que el intelectual 
fracasó como comunicador porque no se cumplieron sus objetivos políticos ${ }^{14}$. Pero claro, hay que negar la mayor pues no se puede hablar en serio ni de una cosa ni de la contraria, como si el devenir histórico se pudiera atribuir a la acción de un hombre sólo o de un solo hombre.

A mi modo de ver, la utilidad de estudiar el periodismo en la obra de José Ortega y Gasset, como en la obra de cualquier gran intelectual, consiste en estas dos cuestiones: por un lado, nos permite extraer en ella lo que de provechoso hay para la formación de futuras generaciones de periodistas. Lo expresa muy certeramente Josep Maria Casasús cuando escribe: "El estudio de los modelos de géneros del pasado es el mejor instrumento para progresar en la experimentación renovadora de los textos. No se puede innovar si se ignora lo que se ha hecho antes en aquella materia" (Casasús, 1991: 88). De este modo, los grandes periodistas del pasado acuden al presente para iluminar nuestro horizonte vital con sus trayectorias ejemplares.

Por otro lado, al estudiar la faceta periodística de Ortega entramos en una nueva dimensión de la biografía de este insigne pensador, y con esta nueva perspectiva comprenderemos mejor el conjunto de su obra. No es insignificante el hecho de que la mayor parte de sus escritos fueran ideados para la volandera página del periódico, con el tono, el ritmo, el espacio por ella impuestos. Si Ortega no hubiera pensado y escrito su obra con mentalidad periodística el resultado sería distinto. Observemos que las páginas de sus tratados no exigen un lector especialmente pertrechado con conocimientos filosóficos, ni dueño de una metodología ni de un lenguaje determinados para simpatizar con su obra. Ello es debido, en mi opinión, a que Ortega, al escribir, nunca perdió de vista al metafórico "Juan", ya se sabe, ese español medio que fue su lector, a quien quiso contaminar con el virus de la "rebeldía constructora". ¿De qué sino de esta peculiaridad trataba el presente artículo?

Por otra parte, creo que la metáfora analizada del "aristócrata en la plazuela" nos ofrece la imagen de un intelectual determinado a utilizar el periódico para sus objetivos político-sociales. Fue su periodismo combativo y militante, movido por una profunda conciencia filantrópica. Y no sólo esto; por lo que sabemos, el propio Ortega estaba seguro de que se le condenaría por elegir el artículo de periódico como vehículo de transmisión filosófica, pero asumió a tiempo que "quien pedantescamente lo desdeña no tiene la más remota idea de lo que está aconteciendo en los senos de la historia” (Ortega, 1983, VI: 354).

No hemos comentado que Ortega también fue periodista pro pane lucrando, como casi todos los de su generación; y además hemos dejado en el arcén la cuestión de hasta qué punto la popularidad alcanzada por los intelectuales que más escribían en los periódicos pudo funcionar en ellos como im-

\footnotetext{
${ }^{14}$ Cfr. Romano, Vicente (1977): José Ortega y Gasset, publicista, Madrid: Akal.
} 
pulso erótico para no abandonar un solo día del ritual periodístico ${ }^{15}$. No se oculta, pues, que el tema del periodismo en Ortega lejos de estar agotado apenas ha sido sugerido en este artículo.

El mencionado Luis Calvo tuvo la suerte de conocer personalmente a Ortega y de tratarlo con asiduidad, sobre todo cuando el filósofo regresó a España tras el exilio. Y no es casual que entre sus recuerdos, Calvo conceda una importancia determinante al periodismo en la vida y obra del gran intelectual:

"El periodismo fue una parte fundamental de la vida de Ortega. Y nadie, después de él, ha conseguido la penetración de pensamiento, ninguno ha alcanzado la belleza literaria y la originalidad, la variedad y la hondura de su filosofía. Deslumbraba a todos y nadie le ha superado...” (Berasátegui, 1987: 262-269).

\section{Referencias bibliográficas}

- Benito, Á. (1982): Fundamentos de teoría general de la información, Madrid: Pirámide.

- Blanco Alfonso, I. (2005): El periodismo de José Ortega y Gasset, Madrid: Biblioteca Nueva - Fundación José Ortega y Gasset.

- (2006): "Ortega o el periodismo circunstancial", Revista de Occidente, n. ${ }^{0} 300$, pp. 49-70.

- (2005): "Para una lectura de la obra periodística de José Ortega y Gasset”, Aportes. Revista de Historia Contemporánea, n. ${ }^{\circ}$ 57, pp. 45-61.

- (2005): “Otoño de 1955: conmoción por la muerte de José Ortega y Gasset”, Revista de Estudios Orteguianos, 10/11, pp. 78-150.

- (2004): “Los géneros periodísticos en José Ortega y Gasset”, en Benavides Delgado, Juan et al. (eds.): Información, producción y creatividad en la comunicación (Actas del $7 .^{\circ}$ Ciclo de Otoño de Comunicación), Madrid: Fundación general de la UCM - Ayto. de Madrid, pp. 731-754.

- (2001): "Modelos, métodos y formatos de las críticas literarias de José Ortega y Gasset", Revista de Estudios Orteguianos, n. ${ }^{\circ}$ 2, pp. 165-174.

- Cacho Viu, V. (1991): "Prólogo" a Cartas de un joven español, edición de Soledad Ortega, Madrid: El Arquero.

- Casasús, J. M. y Núñez Ladevéze, L. (1991): Estilo y géneros periodísticos, Barcelona: Ariel.

- Berasátegui, B. (1987): Gente de palabra. Treinta y siete personajes entrevistos, Barcelona: Plaza \& Janés.

- Espina, A. (1993): El cuarto poder, Madrid: Libertarias/Prodhufi.

${ }^{15}$ Cfr. Timoteo Álvarez, Jesús et al. (1989): Historia de los medios de comunicación en España. Periodismo, imagen y publicidad (1900-1990), Barcelona: Ariel, pp. 23-24. Aquí se presenta la generación del 98 como una operación de marketing y a sus miembros como "intelectuales vedette" de un stars system mediático. 
- Franco, D. (1980): España como preocupación, Barcelona: Argos Vergara.

- Lasaga Medina, J. (1998): “El Espectador como proyecto político”, en Jiménez García, A. (ed.): Estudios sobre historia del pensamiento español (Actas de las III Jornadas de hispanismo filosófico), Santander: AHF.

- Mainer, J. C. (1983, 3. ${ }^{a}$ ed.): La Edad de Plata (1902-1939), Madrid: Cátedra.

- Marichal, J. (1984): Teoría e historia del ensayismo hispánico, Madrid: Alianza.

- Martínez Ruiz, J. (Azorín) (1982): Obras selectas, Madrid: Biblioteca Nueva.

- Ortega y Gasset, J. (2006): Obras completas, tomo V, Madrid: Taurus - Fundación José Ortega y Gasset.

- (2006): Obras completas, tomo IV, Madrid: Taurus - Fundación José Ortega y Gasset.

- (2005): Obras completas, tomo III, Madrid: Taurus - Fundación José Ortega y Gasset.

- (2004): Obras completas, tomo II, Madrid: Taurus - Fundación José Ortega y Gasset.

- (2004): Obras completas, tomo I, Madrid: Taurus - Fundación José Ortega y Gasset.

- (1991): Cartas de un joven español, edición de Soledad Ortega, Madrid: El Arquero

- (1983): Obras completas, 12 tomos, Madrid: Alianza Editorial - Revista de Occidente.

- Ortega y Gasset, E. (1955): "Bebiotai, Bebiotai... Ha vivido, Ha vivido", El Nacional, de Caracas, 3 de noviembre de 1955.

- Redondo, G. (1970): Las empresas políticas de José Ortega y Gasset, Madrid: Rialp.

- Romano, V. (1977): José Ortega y Gasset, publicista, Madrid: Akal.

- Saldaña, Q. (1916): “El Espectador, por José Ortega y Gasset”, Revista crítica hispano americana, Madrid, tomo II, n. ${ }^{\circ} 4$.

- Timoteo Álvarez, J. et al. (1989): Historia de los medios de comunicación en España. Periodismo, imagen y publicidad (1900-1990), Barcelona: Ariel. 